УДК 330.34 .01

\title{
ТЕОРЕТИКО-МЕТОДОЛОГИЧЕСКИЕ АСПЕКТЫ ТРАНСФОРМАЦИИ ЭКОНОМИЧЕСКИХ СИСТЕМ
}

\author{
Л.И. ДРОЗДОВИЧ \\ канд. экон. наук, доцент кафедры «Экономика и право» \\ Белорусского национального технического университета, г.Минск
}

\begin{abstract}
Аннотация
В статье рассматриваются теоретико-методологические аспекты трансформации экономических систем, понятия, этапь и модели трансформации. Возможности трансформации экономических систем исследуются с привлечением концепиии Норта-Уоллиса-Вайнгаста, позволило автору сделать вывод о необходимости дополнения конщепции Норта факторами о пороговых условиях перехода экономики и общества к модернизационной стратегии.

Ключевые слова: экономическая система, трансформация экономических систем, концепции Норта-Уоллиса-Вайнгаста.
\end{abstract}

Abstract

The article deals with theoretical and methodological aspects of the concept, stages and models of transformation, the possibility of transformation, involving the concept of NorthWallis Weingast. There are considered the institutional approach the study of the transformation process.

Key words: economic system, transformation of economic systems, concept of NorthWallis Weingast.

\section{ВВЕДЕНИЕ}

Современный мир переживает сложный период радикальных трансформаций, затрагивающий базовые основы экономической систем различного уровня и проявляющиеся в снижении их системной устойчивости, сопровождающиеся кризисными явлениями. Конец XX-XX1 века ознаменовался кризисами, охватившими в 1990-х годах постсоциалистические страны, сопровождающийся разрушительными масштабами, превратив ряд из них в результате исторического выбора модели развития в динамично развивающиеся системы, а множество других стран, отказавшись от использования стабилизационной политики и преодоления серьезных структурных деформаций, постепенно приобрели характер депрессивных экономических систем. Кризисы 2007, 2008, 2011 гг. охватили практически всю мировую систему, перекинувшись из финансового сектора в реальные отрасли экономики, что сопровождалось обострением противоречий, хаотичностью экономической динамики, нарастанием остроты глобальных экономических кризисов.

В русле глобальных тенденций происходят преобразования в национальных экономических системах, отличающиеся различной мерой, глубиной, масштабами и скоростью процессов реформирования.

Трансформации радикального характера, охватившие постсоциалистические страны, вызвали резкие изменения траектории развития экономических отношений. Как показывает опыт выбора траектории развития этих стран, недостаточный учет в состоянии экономических отношений особенностей их предшествующего развития, деформация институтов, несоответствие формирующихся институтов реальным экономическим отношениям, серьезно ограничивает возможности трансформации - стабилизации- модернизации в экономических системах. Множественность факторов развития, 
их непрерывная трансформация приводят к плюрализму национальных экономических моделей. Все это означает, что на историческом пути фактически у всех стран сохраняется многовариантность социально-экономического развития. Но где возникает возможность многовариантности, там существует проблема выбора оптимального, дальнейшего пути развития, поскольку затянувшаяся инерционная стадия усиливает реставрационные механизмы. В этой связи становится очевидным, что для выбора пути развития переходной экономики требуется анализ практики собственных системных экономических трансформаций, а также обобщение опыта адаптации развитых стран к вызовам мирового рынка.

Процессы трансформации экономических систем являются неизбежным следствием общих закономерностей развития, что предполагает не только осмысление общего, но и специфики их осуществления, учет современной экономической динамики. Также усиливающееся взаимодействие национальных экономик, ускорение глобализационных процессов - в существенной степени оказывает влияние на выбор вектора экономической трансформации, скорости их перехода с инерционной стадии к активной фазе преобразований.

В целом, многогранность, сложность и противоречивость влияния этого процесса на экономический рост трансформационных экономик постсоциалистических стран, а также неоднозначно оцениваемые результаты этих стран по использованию макроэкономических стабилизационных моделей, вызывает необходимость обоснования теоретических основ и формулирования системных методологических подходов трансформации экономических систем, определению ключевых элементов и регуляторов в системе трансформации экономики. Сегодня, через 20 лет с начала постсоциалистических реформ, постепенно формируются общие подходы к оценке этих процессов, очевидная межстрановая дифференциация по уровню развития (между странами бывшего соцлагеря), что свидетельствует о различных по уровню эффективности страновых структурных трансформационных стратегиях, характеризующихся различной степенью неопределенности, устойчивости, способностью к адаптации. Обобщение опыта стран трансформационной группы позволяет, по мнению Лемешевского И.М., одного из ведущих отечественных теоретиков в области трансформации экономических систем, « в качестве основных концепций переходного периода следующие разновидности: «социальная рыночная экономика, олигархический капитализм, восточный капитализм, государственный капитализм, рыночный социализм» [1], каждая из которых различается мерой и величиной трансформационных издержек. Отсутствие системной концепции преобразований экономик постсоциалистических стран с учетом уже сформированных подходов является одной из причин высоких трансформационных издержек. Признав необходимость качественных сдвигов в социально-экономическом развитие постсоциалистических стран экономическая наука обнаружила не только недостаточность теоретического знания, но и явно ограниченные возможности получения новых представлений и выявления закономерностей, в рамках традиционной классической парадигмы, отвечающим новым вызовам. В научном плане проблема структурных трансформаций, моделей и типов экономических систем, методов перехода к социально ориентированной рыночной экономики пока находится в начальной стадии разработки, несмотря на то, что в начале 2000-х постоянно рассматривались общие контуры социальноэкономических преобразований: вопросы экономической роли государства, использования отдельных механизмов по макроэкономической стабилизации, социальной ориентации реформ. Появились работы видных белорусских и российских экономистов, в которых отражалась их точка зрения на состояние отечественной науки и практику осуществляемых реформ, но остающиеся разногласия касаются сущности трансформационных процессов, определении общего и особенного в этом процессе, выработки механизмов, обеспечивающих переход от инерционной стадии к более активной. Весьма 
существенно различны точки зрения по оценке меры инерционности развития системы, и возможности (или необходимости) перехода к более активной стадии трансформации национальной экономики. [6, 7, 8 и др.] Это обусловлено как сохраняющимся упрощенным пониманием сущности переходных процессов в ходе рыночных преобразований, экономической либерализации, так и новыми особенностями формирующегося информационного общества.

\section{РЕЗУЛЬТАТЫ И ИХ ОБСУЖДЕНИЕ}

Приобретение Беларусью в 90-х гг. государственного суверенитета существенно актуализировало исследование вопросов развития национальной экономики в условиях разрушения единого народнохозяйственного комплекса, ее адаптации новым условиям. Для этого ответственного периода положительным подходом выступило то, что белорусская экономическая наука оказалось не зацикленной на доминировании одной из школ мировой экономической мысли, а пыталась найти собственные подходы к структурным преобразованиям, обоснованию их необходимости, разработке соответствующих механизмов. Важным общепринятым методологическим подходом для развития экономической школы имеет доминирующее понимание того, что в трансформационный период постсоциалистических стран функционирует переходная экономика, которая находится в состоянии неравновесного состояния, имеет временный характер, неустойчива вследствие особенностей, длительности перехода административно- командных механизмов управления к преимущественно рыночному регулированию.

Наиболее общий подход к сущности понятия «трансформация» был определен в экономической теории еще в середине прошлого века. Термин «трансформация», а точнее - большая трансформация, как целостное строевое преобразование, в том числе культурное и цивилизационное, был введен Карлом Полани в 1944 году, согласно концептуальным воззрениям которого в рамках трансформации осуществляется эволюционный переход к новой экономической системе.[2] Существующие методологические подходы, посвященные выявлению причин, закономерностей и стадий развития систем, рассматриваемые в работах $[3,4,5,6,7]$, представляют трансформационную экономика не только в контексте масштабов и используемых при этом механизмов преобразований, но и с учетом динамики двух аспектов: самоотрицания, нисходящее развитие «старой» системы, которое усиливает отрицательное взаимодействие между элементами системы; зарождения и развертывания новых структурных элементов системы, повышающих степень ее адаптивных возможностей, смену институтов при сохранении инерции и функционировании отдельных элементов старой системы, наличие институциональных разрывов. И в этой связи, безусловно, «трансформационная экономика не представляет целостную социально-экономическую систему, поскольку она противоречива, неоднородна, гетерогенна» [2].

Но, прежде тем перейти к исследованию экономической системы следует понять, что представляет собой система вообще. Жизнедеятельность людей не может не осуществляться через различного рода системы: природные, социальные. Известный российский ученый Гумилев Л.Н. определил в работе «Струна истории» глубинные, сущностные понятие «система» - «система- это, такой подход, когда внимание обращается не на персоны, которые ее составляют..., а на отношения» [15]. «...Реально существующим и действующим фактором системы являются не предметы, а связи, хотя они не имеют ни массы, ни заряда, ни температуры» [16]. Связи в системе могут быть как положительными, так и отрицательными, причем некоторые связи подсистемы на протяжении жизни могут менять знаки. Даже эти некоторые закономерности показывают, «что любая система не статична, а находиться либо в динамическом равновесии, либо в движении от какого-то толчка, импульс которой находится вне данной системы» В це- 
лом, наличие всеобщих связей, создающих динамические стереотипы, более или менее устойчиво, но никогда не вечно.» [16]. Мера устойчивости системы определяется не ее величиной или массой, а набором связей, выход за пределы которых влечет либо гибель, либо бурное развитие. Этим, представляется и «создается возможность эластичности системы, позволяющей ей либо амортизировать внешние воздействия и даже развиваться, ибо «многосвязная» система восполняет ущерб перестройки связей.» [16]. Полагаем, в контексте управления трансформацией системы необходимо определить такие импульсы, которые надлежащим образом переформатируют взаимодействие между элементами, что усилит ее меру устойчивости и адаптационности.

Существующие системы неоднородны, с точки зрения особенностей их функционирования выделяют « системы четырех типов: открытые, закрытые, жесткие и корпускулярные. Открытые системы - это вид, который получает запас энергии в виде пищи, который поглощает, например, животные. Они эту пищу добывают, размножаются, дают потомство, умирают, отдают свое тело матушке Земле, Это открытая система, которая получая энергию извне, обновляется. Закрытая система получает запас энергии единожды, и только в рамках определенного времени она функционирует, а после прекращения подачи энергии - процесс кончается. «Жесткая система - это хорошо отлаженная система, где нет ни одной лишней делали. Она работает только тогда, когда все винтики на месте...Но в идеале жесткая система должна отличаться полной слаженностью частей. Она очень эффективно работает, но при поломке одной детали она останавливается полностью и полностью выходит из строя». Корпускулярная система - эта система взаимодействия между отдельными частями, не связанными между собой. Но, тем не менее, нуждающиеся друг в друге. Социальная система - это жесткая система открытого типа, потому что она получает постоянно культурные традиции, за счет чего социальные объединения существуют. Получает из истории, из памяти прошлого, с одной стороны. А с другой, они тесно связаны; но, будучи сломанной, требует вмешательства извне. А не восстанавливается сама. Принимая во внимание вышеприведенные общие рассуждения о системе и ее некоторых свойствах определим понятие «экономическая система».

Экономическая система представляет целостный объект, состоящий из множества взаимосвязанных элементов в виде совокупности как производительных сил и системы отношений между людьми по поводу производства, распределения, обмена и потребления. Как система она состоит из элементов (подсистем), находящихся определенных отношениях (взаимосвязях) между собой. Общепринятый подход классификации экономических систем по уровням обуславливает необходимость исследования взаимосвязанной трансформации экономических систем разных уровней, связанную с переходом на новую модель и новым технологическим укладом. При этом ключевая роль в процессе структурной трансформации отводится предприятиям, как базовому элементу экономической системы. Переход системы в новое состояние предполагает качественное изменение всех ее составляющих элементов различных уровней.

По мере накопления опыта и оценки теория трансформации как совокупность представлений и закономерностей, развивалась с развитием экономической науки, что постепенно приводило к изменению общих методологических установок: использованию анализа, привлечения принципов системности, анализа механизмов самоорганизации, учета нелинейных кумулятивных эффектов, сложных взаимодействий и взаимосвязей в экономической системе с учетом иерархии. Вследствие синтеза таких областей знания как теория организации, термодинамика неравновесных процессов, теории организации химических и биологических систем возникла новое теория- синергетика. Главной идеей синергетического подхода стало представление о процессах самоорганизации и в сложных системах, находящихся в неравновесном режиме функционирования, что означало формирование нового представления к оценке в подходах динами- 
ки экономических процессов: степень ее инерционности, определении границ, в которых возможна воздействие и управление экономической динамикой. Функционирование экономической системы регулируется системой прямых и обратных связей, положительных и отрицательных. Отрицательные связи содержат существенный реставрационный потенциал и направлены на сохранение действующих структур и взаимодействий. Соотношение положительных и отрицательных обратных связей обеспечивает устойчивость и ее возможности к преобразованиям, количественный рост и качественной развитие. Важные характеристики системы характеризуются сложной взаимосвязью между явлениями устойчивости, адаптируемостью. Адаптируемость системы рассматривается как свойство, ее способность достигать цели задачи, реализовывать функции с учетом изменения внешних условий. Нарушение свойств устойчивости и адаптируемостми происходит вследствие накопления изменений в элементах системы, во взаимосвязях между ними. При этом рамках определенного периода система может функционировать в системе нарушенной системе координат, однако исчерпание возможностей адаптивного развития и поступательной модернизации приводит к критической точке и вступает в состояние пермаментной неустойчивости. Постепенное разрешение накопленных противоречий будет способствовать созданию новому качеству первичных элементов, их взаимосвязей и их движению в направлении к более сложной системе. Стабильность системы достигается большим числом соответствий, оптимизацией взаимосвязей. Определенные подходы в рассмотрении закономерностей переходных процессов дает привлечение математической теории катастроф. Определение катастроф как скачкообразных изменений, возникающих как реакция системы на постепенное изменение внешних условий формулирует, например, В.И. Арнольд, теория катастроф рассматривает вопрос об условиях, при которых изменение параметров системы вызывает перемещение данной точки в фазовом пространстве и области притяжения к другому положению равновесия» [9], что позволяет определить их воздействие как скачок в развитии системы. Системы обладают пороговыми состояниями, переход к которым способствует существенному качественному изменению протекающих в ней процессов, к изменению самой системы, по мнению академика Н.Н. Моисеева. Следовательно, модернизация в структуре системы может происходить в условиях накопления количественных изменений на уровне ее частей, элементов, достижение критического значения изменений ведет к качественной перестройке экономической системы. В этом контексте трансформация характеризуется критическими уровнями состояний в развитии систем в ходе которых происходит определение новой траектории движения и условия ее функционирования. В случае достижения системой порогового значения коренным образом трансформирует и управляющие ею механизмы, что предопределяет различные варианты ее будущего состояния.

Множественность состояний системы и траекторий ее характеристик обусловлена механизмом бифуркаций, которая в традиционной трактовке означает «расщепление» траектории развития на множество вариантов, реализация которых оказывается зависимой от воздействующих на нее совокупности факторов [2]. В момент бифуркации выбор дальнейшего пути развития происходит под воздействием эндогенных и экзогенных факторов в значительной степени случайно, но не произвольно, а в области возможных решений. Система этих факторов создает ситуацию, при которых бифуркация становится неизбежной, что вызывает необходимость определять границы, при которых система будет способна к адаптации. Потеря устойчивости происходит по мере приближения системы к пограничной критической зоне, в рамках которой нарушается целостность системы, происходит существенное нарушение взаимодействия ее элементов, усиление отрицательных кумулятивных механизмов, что способно вызвать ее дестабилизацию. Оценка и мера дестабилизации может служить оценка состояния системы с позиции ее целостности, размер и динамика трансформационных издержек, кото- 
рые возрастают по мере пролонгации системы в состоянии неустойчивости и потере способности к адаптации.

Так, теория трансформации имеет прикладное значение в процессе формирования конкретных национальных стратегий трансформации. С одной стороны, определенные на ее основе закономерности позволяют понять динамику отдельных параметров системы, а также выявить основные факторы сбалансированного перехода. С другой стороны, определяя границы адаптивности системы и критические значения давления на систему, при которых качественный скачок становится неизбежным, теория трансформации рассматривается как инструмент прогнозирования будущих состояний системы, позволяющих, в нивелировать веер отрицательных бифуркаций. В этом смысле трансформация выступает как сознательная целенаправленная дестабилизация системы в результате действия комплекса факторов, определяющих рациональный подход к развитию (определение цели, выбор и обоснование механизмов, выбор оптимальной парадигмы).

В рамках подхода Ю.М. Осипова «Бифуркационный феномен - это феномен качественной неопределенности, когда единое (для социума - целостное, системное, комплексное, органическое...) качество вдруг распадается... уступая место сначала возможным, а затем уже в действительно новым качествам, когда имеет место борьба качеств, их отбор в ходе стихийной или управляемой конкуренции. Бифуркационная ситуация-ситуация качественного варева, энергоинформационного, системопоглащающего и системообразующего котла». Переходные процессы, имеющие временный характер, по своей сути вызывают нарушение устойчивости, «прошлого качества» в системной организации и поэтому не могут не осуществляться в конфликтной, кризисной форме, содержащей существенный реставрационный потенциал.

В широком аспекте трансформация социально-экономической системы как процесс изменений в социально-экономическом и экологическом развитии, опирающийся на институциональные преобразования.

В ряде работ, посвященных проблемам трансформации $[4,10,5]$ рассматриваются особенности формационного и цивилизационного подходов к развитию экономических систем, обосновывается что оба подхода дополняют друг друга и характеризуют общество с различных сторон и в разных системах координат, путь развития человеческой цивилизации, что эти процессы происходят методами трансформации- стабилизациимодернизации. Известные московские экономисты Бузгалин А.В., Колганов А.И., опираясь на мировой опыт трансформационных процессов, а также концептуальные подходы реформирования европейских экономик реального социализма, формировавшиеся в 90-х годах, в работе «Теория социально-экономических трансформаций: прошлое, настоящее и будущее экономик «реального» социализма в глобальном постиндустриальном мире» определил общие направления и условия реализации трансформации в экономике, касающиеся радикального изменения в отношениях присвоения, функционировании финансового капитала, элементов и способах обеспечения экономической координации, а также определил основные модели осуществления трансформационных сдвигов каждая из которых базировалась на определенных механизмах трансформации [7]. Нельзя не подчеркнуть, что в этот период особенно актуально встала проблема формулирования и выбора новых посттрансформационных стратегий в отношении сроков реализации стратегии, механизмов движения к новой экономике в течение последних десятилетий, в результате которых стала формироваться новая область экономической теории. Базовым элементом теории и методологии структурной трансформации экономических систем в рамках формирующейся политэкономии трансформации стало выявление общих теоретико-методологических основ структурной трансформации экономических систем и механизмов их реализации в условиях становления рыночной экономики. 
Следует отметить, что основное содержание процессов трансформации определяется разработкой конкретно-исторических или страноведческих моделей, в полной мере учитывающих внутренние и внешние факторы современного развития страны, не допуская при этом неэффективного копирования упрощенных схем организации экономической системы. Национальная трансформационная модель экономики призвана решить проблему выбора стратегического направления социально-экономических преобразований, обеспечения последовательной и непротиворечивой реализации избранной стратегии модернизации экономики. Вместе с тем, реализация трансформации экономической системы существенное влияние оказывает инерционность унаследованного экономического строя, что усиливает вероятность реставрации старых институтов.

Игнорирование указанных базовых основ, необходимых для реализации трансформационной стратегии, отдельными странами, обусловило необходимость продолжения реформ, но уже в контексте проведения модернизации экономики. Необходимость социально- экономической модернизации большинства постсоветских стран была обусловлена незавершенностью социально-экономических трансформаций в этих странах, поскольку саморазрушение многих основ псевдосоциалистического государства оказалось во многом по своему существу фиктивным. Квазисмена общественных систем не придала должного импульса (толчка) к развитию, не позволяла преодолеть отставание на основе перехода к новому качеству роста. В рамках модели переходной экономики должна формироваться новая конфигурация экономического взаимодействия между элементами системы, создание которой возможно только на основе учета общего и особенного в этом процессе. Теоретико-методологические подходы в области трансформации экономики, преимущественно господствовавшие в конце 80-х и начале 90-г базировались на общей либеральной модели макроэкономической стабилизации, предложенную Вашингтонским консенсусом, согласно которому трансформирующейся группе стран достаточно использовать в своей практике указанную модель, не учитывая национальные культурные особенности. Однако современные практики реализации структурных сдвигов свидетельствуют не только о вероятности многовариантного развития, но и необходимости учета культурных, исторических и экономических аспектов страны в процессе реформирования экономической системы и формировании оптимальной модели переходной экономики. Концепция системной трансформации касающихся всех бывших централизованно планируемых экономик должны определять не только тип системы, к которой стремятся трансформирующиеся страны, но и выбора механизмов (способа) проведения системных изменений и степени учета культурной адекватности вводимой системы, иначе говоря, зависимости от культурного пути [7].

Согласно JI. Бальцеровичу, первому премьер-министру Польши, « минимальное количество вопросов, которые можно поставить в процессе формирования трансформационных стратегий, сводится только к двум: откуда и куда идем, а «в немного менее краткой форме проблематика трансформации может быть разделена на три части (вопроса). Во-первых, диагноз, каков пункт старта; во-вторых, конечный пункт- строй; в-третьих, способ перехода от начального состояния, являющегося предметом диагноза, к определенному конечному состоянию. Тот, кто не в состоянии сформулировать диагноза и не в состоянии сформулировать определенного конечного состояния, также не в состоянии сказать, как переходить, потому как не знает, от чего к чему должен переходит» [11]. Аналогичный подход рекомендуется Р. Полиньски: «(проблема) системной трансформации заключается в определении методов, средств, темпов изменений и требует определения соответствующих направлений трансформации» [12]. С учетом определенных в вышеуказанных исследований общих и специфических закономерностях основной теоретическо-практической проблемой системной трансформации для всех национальных экономик является перераспределение роли (функции) государства в экономике, построение институтов и 
рыночных механизмов, функционирующих в согласии со стратегическими приоритетами государства.

Первый - это формирование регулятивной функции государства в процессе транзитивных стратегий. По мнению Р.Полиньски: «изменения могут быть спонтанные и / или управляемые, руководимые государством. Здесь нет дилеммы: спонтанность или декреты свыше. Однако же в действительности в значительной области мы имеем дело с дополняющими друг друга обоими подходами. Определенная часть строевых нововведений появляется спонтанно, но большая часть из них - это результат действий государства, реализации его концепций или повторения чужих образцов. Поэтому роли государства в трансформируемой экономике нельзя и не следует сводить к дилеммам: спонтанное или управляемое государством развитие, рынок или государство, либерализация или государственное вмешательство, а сформулировать в форме дилеммы: большая или малая степень государственного вмешательства в экономику, особенно по отношению к рынку» [12]. В данных концептуальных воззрениях убедительно сочетаются не только эффективный опыт трансформационного регулирования постсоциалистических стран, но положения базовых постулатов неокейнсианской теории: каждая современная экономика, каждый современный рынок регулируется государством - прямо или косвенно, особенно если реализует оно определенные общественные цели. Отличия в том, что в каком диапазоне и при помощи каких средств (инструментов) - экономических или административных - ведется системная трансформация.

Очевидно, что в условиях слабого и институционально неразвитого рынка только государство в состоянии продвигать и стимулировать экономический рост, вводить в действие факторы, позволяющие преодолеть структурные неравновесия (всеобщие и частичные) или трансформационную рецессию. Опыт развития рыночной трансформации стран ЦВЕ как стран осуществивших преимущественно быстрые социально-экономические трансформации может быть практически полезен прежде всего в контексте учета трансформационных проблем, учитывая, что страны ЦВЕ имели аналогичные стартовые условия: отсутствие естественной структуры производства, искаженные цены, доминирование государственной собственности. Как показал опыт эффективно трансформирующихся экономик сложные процессы переориентации экономики на производство потребительских товаров и услуг, приватизации, повышения эффективности использования ресурсов, формирования новой экспортной базы должны быть регулируемы. Протекая стихийно, они могут привести к неоправданным потерям производственного и научно-технического потенциала, к еще более серьезному ухудшению позиций национальной экономики на мировом рынке. В целом, государство в вопросах структурной трансформации, особенно на ее первых этапах, вынужденно проводить политику жестких экономических, а иногда и прямых административных мер.

Процесс системной трансформации еще не закончен, в отдельных странах он находится на начальном или среднем этапе, однако опыт системных реформ бывших стран СЭВ, направленных на преобразование как самого общества , так и отдельного человека, перемены в общественном сознании, обуславливает необходимость уточнения регулирующей роли государства в структурных трансформациях. Реализация модернизационной стратегии невозможно без продолжения трансформационной стратегии активизации государства по следующим направлениям:

Во-первых, необходимо поддерживать частный бизнес, конкурентную среду, убрать чрезмерные ограничительные государственные инструменты, которые тормозят развитие зрелой предпринимательской среды, и наоборот создают широкое поле для инноваций, способствуют формированию инновационной модели в белорусской экономике, базой которой должна стать инновационная инфраструктура. 
Использование стимулирующих механизмов создания инновационных продуктов должны быть направлены на формирование инновационных сетей, увязывающих в одну цепочку процесс от изобретения до его воплощения в конкретном продукте и до коммерциализации полученной инновации на рынке.

Во-вторых, все предприятия, независимо от их формы собственности, необходимо разделить способные и не способные к инновациям, первым необходимо оказывать государственную поддержку в различных формах, от вторых постепенно избавляться, с помощью не только экономических методов (штрафов, снижения закупочных цен и т.д.), но и административных мер (объединение, поглощение, ликвидация). Такие меры по структурному реформированию должны быть основаны на государственных отраслевых программах.

В-третьих, формировать институты, создающие в экономике обширный слой малых и средних инновационных фирм, способных не только создавать большое разнообразие инновационных продуктов, но и постоянно дифференцировать их структуру и коммерческую ориентацию. Современные научные и технологические процессы свидетельствуют, что самая высокая инновационная активность фиксируется в странах с высоким уровнем зрелых рыночных механизмов и предпринимательской среды, а также в страна[ осуществивших быстрые структурные реформы. В странах, где государство имеет большую роль в экономике, внутренняя инновационная активность существенно слабее, и упор делается на привлечение зарубежных инноваций, что на первом этапе вполне естественно.

Это обусловлено тем, что быстрые структурные реформы сокращают период неопределенности и препятствуют мобилизации оппозиционных групп, способных блокировать реформы, а последовательные, в свою очередь, предполагают меньшие социальные издержки в коротком периоде, поскольку при их проведении избегают нарушения устоявшегося положения путем одновременного введения реформ во многих секторах экономики. При более детальном рассмотрении трансформационных переходных экономик, можно увидеть, что различия между быстрыми и последовательными реформами незначительны.

Отсутствие политических реформ в странах, предпочитавших постепенное вхождение в рынок, приводило к т.н. «ловушке частичных реформ», поскольку со стороны чиновников, депутатов, директората государственных и полугосударственных предприятий и банков возникало и нарастало сопротивление дальнейшим рыночным реформам. Возникающая рента от частично либерализованных рынков позволяла получать им высокие доходы от лоббирования, протекционизма, избирательного правоприменения и прочих нерыночных практик и делала крайне незаинтересованными в создании четких прозрачных неизменных правил. Не допустить создание или сломать такую систему гораздо проще на самых ранних стадиях реформирования, когда она еще не возникла или слаба. Если в стране отсутствуют политические реформы, то рано или поздно возникает сговор между чиновниками, депутатами и отдельными бизнесменами, и государство перестает выполнять свои функции (защита прав собственности, гарантия равных условий, выработка четких, прозрачных и неизменных правил игры) и начинает заниматься такими специфическими функциями как «огосударствление» бизнеса, номенклатурной приватизацией.

С помощью целенаправленной трансформации общество производит необходимые изменения, системные коррективы, с тем чтобы избежать накопления противоречий и их стихийного разрешения, При этом возникает необходимость поддержания относительной устойчивости системы на основе обеспечения регулируемости осуществляемых трансформаций.

Существенным в теории остается вопрос об объективных границах трансформации, связанных с критическими параметрами в развитии системы, за которыми нару- 
шение устойчивости принимает необратимый процесс, система теряет управляемость, переходные процессы выходят из-под контроля и их развитие приобретает стихийный характер. В этом случае, если внутренняя стабильность системы еще поддерживается на основе ее способности к адаптивному развитию, функционирование системы осуществляется на основе механизмов самоорганизации, в условиях, когда механизмы адаптивного механизма исчерпаны, нарастание неустойчивости способно привести к саморазрушению системы.

Следует отметить, что основное содержание процессов трансформации определяется разработкой конкретно-исторических или страноведческих моделей. В полной мере учитывающих внутренние и внешние факторы современного развития страны, не допуская при этом неэффективного копирования упрощенных схем организации экономической системы. Национальная трансформационная модель экономики призвана решить проблему выбора стратегического направления социально-экономических преобразований, обеспечения последовательной и непротиворечивой реализации избранной стратегии модернизации экономики. Вместе с тем, реализация трансформации экономической системы существенное влияние оказывает инерционность унаследованного экономического строя, что, зачастуя усиливает вероятность реставрации старых институтов. Данные тенденции необходимо учитывать при формировании регулирующих функций государства в переходной экономике с учетом периодизации.

Важным критерием разграничения различного рода переходных процессов является оценка их результатов, последствий, сопоставимости исходного и нового состояния системы. При этом параметрами условной периодизации следует рассматривать оценка меры, степени, формы и продолжительности нарушения устойчивости системы.

Этапы и модели трансформации могут быть выделены на основе качественных преобразований отношений в новую систему. В рамках первого этапа- подготовительного- происходят процессы саморазложения старой системы при явных или скрытых попытках ее реформировании без изменения ее сущности. Он заканчивается тем, что системный кризис старой системы проявляет себя как социально-экономический и социально- политический кризис. В СССР этот этап занял 1985-1991 гг., Польше 1980-1989 гг., Венгрия - 1968-1988 гг. Второй этап входом в трансформационную несбалансированность характеризуется активными институциональными преобразованиями, направленными на качественное изменение производственных отношений. Этот этап характеризуется разрушением старых и слабостью новых регуляторов экономической динамики и сбалансированности, что было обусловлено отсутствием сложившихся механизмов саморегулирования воспроизводственных отношений на собственной основе.

Рассмотрим основные базовые модели, в которых отражаются вышеуказанные закономерности: модель государственного рыночного реформирования (1), государственно-корпоративная модель рыночной трансформации (2), либеральнокорпоративная модель рыночной трансформации (3). Рассматриваемые модели систематизированы с точки зрения исторической последовательности генезиса моделей трансформации и глубины изменений в исходной системе экономических отношений. Отличительной чертой этой модели (1) следует выделить ограничение качественных изменений одним сектором экономики, доминирование инерционности, постепенности изменений, кооперация с глобальным капиталом без подчинения последнему. При достаточно широкой эспансии мелкой собственности и совместных предприятий господствующим способом координации ресурсов продолжает оставаться централизованный бюрократический контроль государства. доминирующий над рыночным регулированием, собственность остается поз государственным корпоративным контролем. Такая модель может обеспечивать как быстрый рост (Китай), так и стагнацию (СССР конца 80-х годов). С методологической точки зрения эта модель характеризуется доминированием 
первого вектора трансформационного процесса, но при относительной слабости второго (либерализации) экономических отношений. По характеру развития она является инерционной и длительной по времени функционирования. Государственнокорпоративная модель рыночной трансформации характеризуется во многом схожими чертами, предполагает не реформирование социализма, а его демонтаж. При этом происходит качественно более радикальное перераспределение экономической власти, контроля и собственности. Основными чертами модели являются постепенные рыночные реформы при сохранении ведущей роли государства с активным использованием административных методов управлением. Существенным признаком этой модели, завершающим конструкцию,- продолжение патерналисткой социальной политики в рамках которой на место самоорганизации индивидов приходит организации и система тотального контроля со стороны.

Представляется, что существенным фактором, определяющим возможности и границы системных преобразований в экономике, способствующим сокращению отрицательных связей, являются институты. Для выявления этих связей рассмотрим основные положения неоинституциональной теории. Неинституциональная теория, в отличии от теорий мейстрима, рассматривает экономические проблемы с учетом политических, культурных и других факторов, а также признает, что субъекты не всегда руководствуется принципом экономической целесообразности. В рамках институционального подхода национальную экономику формирует «социальный человек», который при принятии экономических решений принимает во внимание не только показатели, но и существующие в обществе традиции, законы и нормы хозяйственного поведения.

«...Человеческое поведение, писал Д. Норт, гораздо сложнее того, которое описывают экономисты в своих моделях, опирающихся на функции индивидуальной полезности. Во многих случаях следует говорить не только о максимизации личной выгоды, но и об альтруизме и самоограничении, которые влияют на результаты выбора индивида» [13].

Основатели институциональной школы Т. Веблен, У. Митчелл и др. рассматривали институты как образцы и нормы поведения, а также привычки мышления, влияющие на выбор стратегий экономического поведения. В отлиличии от институционалистов «старой школы», сторонники неоинституционального подхода Р. Коуз, Д. Норт и другие рассматривают институты в более широком аспекте в качестве важнейшего фактора экономических взаимодействий, задающих структуру побудительных мотивов.

Институт выступает как распостраненный или действий, способ мышления, запечатленный в привычках социальных групп и обычаях народа страны, которые обусловлены социально-экономическими и культурными процессами. В рамках неоинституционального подхода современная экономика есть совокупность привычек, обычаев и традиций, которые рассматриваются как система профильных институтов. Институты, структурируя взаимодействия хозяйствующих субъектов, по мнению Лемешевского И.М. «посредством формирующимся правилам игры, заключенным соглашениям, в рамках которых вырабатываются совместные нормы действий, по сути создают способ организации экономических взаимодействий (форму хозяйствования, алгоритм принятия решений), детерминированный правилами поведения, способствуют уменьшению неопределенности в деятельности субъектов хозяйствования. Субъекты через свои действия и накапливаемый опыт хозяйствования создают институты, а институциональная среда сама способствует формированию определенного типа граждан» [1].

И в рамках действия данных закономерностей, обуславливающих способ развития системы, представляется, что качество институциональной среды, может как формировать стабильность, устойчивость системы, ее адаптационные возможности, так и создавать отрицательные связи и взаимодействия. И в этой связи, полагаем, что господствующие в обществе институты обуславливают не только выбор модели трансформационных 
стратегий, определяемых государством, но и существенно ограничивают (или расширяют при определенных условиях) возможности к активной стадии трансформации.

В связи с четко обозначенной с 2000-х тенденцией ревизии курса на трансформацию экономики и переходом на «модернизационную» риторику в экономической теории появляются институциональные концепции, пытающиеся объяснить причины срывов модернизации исключительно «особенностями предшествующего развития», что предполагает искать свой «особый» путь, который строился бы с учетом традиционных национальных ценностей. Особый интерес в рамках рассматриваемой темы представляет концепция Норта-Уоллиса-Вайнгаста о возможности перехода транзитивных обществ в состояние развитых экономических систем не только в институциональном, технологическом, но и в полноценном социальном аспектах.

По мнению Плискевич Н.М. - «по сути, когда мы сегодня говорим о подлинной модернизации,, а не просто модернизации технологической, инструментальной, то имеем переход от одного общественного устройства к другому.» [14]. В отличие от господствующих в экономическом мейнстриме представлений о поступательном развитии экономики и общества Норт исходит из того, что современный мир - мир «неопределенности и непрерывных изменений, эволюция которого идет по новым и неожиданным путям». Гумилев Л.Н., выявляя закономерности развития этносов на протяжении сотен веков, определяет: «Историческое время- это как бы звучание струны, которую щипнули, и она медленно затухает. Развитие этноса идет не вперед, и не назад, и не по кругу, а оставаясь на одном месте и постоянно вибрируя как струна» [15].

Однако «накопленный к настоящему опыт многих стран так называемого развития свидетельствует, что при национальных особенностях, которыми не следует пренебрегать, есть целый ряд принципов, которых необходимо придерживаться, если действительно имеется желание модернизировать экономику и общество в целом с соответствии с императивами уже нового, постиндустриального общества.» В основе трансформаций лежит сознательная деятельность людей, стремящихся «добиться результатов, снижающих неопределенность» в соответствии с их представлениями о последствиях таких действий. Источником подобных представлений являются «ментальные конструкты, основанные на историческом и современном опыте. А потому культура и стратегия управления, сформированная таким образом, не только определяет эффективность общества, но и также возможность формирования институтов, создающих систему сдержек и противовесов для игроков. В зависимости от того, каким образом она решается обществом, формируется институциональная среда, оказывающая воздействие на развитие страны, ее способность к восприятию и производству инноваций» [14]. Согласно концепции Норта-Уоллиса-Вайнгаста переход на траекторию развития эффективных государств был обусловлен переходом состояния «естественного государства» с присущими ему «порядками ограниченного доступа» «К зрелому государству», институциональная структура которого характеризуется как «порядки открытого доступа». В своем историко-экономическом анализе причин такого положения Норт и его коллеги выдвинули идею необходимых пороговых условиях перехода к современному обществу с порядками открытого доступа: принцип верховенства права для элит, то есть равенства всех граждан перед законом; построение институциональной структуры организации общества, не зависящей от персональных качеств личностей, возглавляющих конкретные институты (требование институциональной обезличенности). С позиций Норта и его коллег, главный фактор перехода к новым социальным порядкам находится во внутриэлитных отношениях. Поэтому его рецепты для обществ, стремящихся к такому переходу, направлены на максимальную возможную подготовку к нему элит в рамках совершенствования порядков ограниченного доступа. 
Если элиты «запаздывают» по сравнению с обществом, инициируемые «снизу» социальные преобразования, как правило оказываются неподготовленными и в результате происходит разбалансирование действующих институтов.

Слабость институционального порядка трансформирующихся стран, по мнению известного польского экономиста Р. Полиньски, «порождают два вида конфликтов и препятствий в их экономическом развитии. Во-первых, снижение эффективности рынков, вызывающее и усиливающее случайность и дезорганизацию в распределительных отношениях (в области доходов хозяйственных субъектов, фондов публичного сектора и физических лиц), а в результате - снижение качества рыночного регулирования. Отсутствие обратной связи между добросовестной конкуренцией и дифференциацией продуктивности (производительности, рентабельности) и доходов. Это ослабляет и разрушает позитивную спонтанную мотивировку прогрессивных приспособлений и нововведений (технологических, организационных и др.). Без такой обратной связи дифференциация доходов теряет свое, направленное на развитие, значение. Во-вторых, создание непродуктивных общественных расходов, в том числе социальных трансфертов, рост которых свидетельствует не о реализации идеи государства благополучия, а о масштабе патологии институционального порядка» [12].

Во-вторых, все предприятия, независимо от их формы собственности, необходимо разделить способные и не способные к инновациям, первым необходимо оказывать государственную поддержку в различных формах, от вторых постепенно избавляться, с помощью не только экономических методов (штрафов, снижения закупочных цен и т.д.), но и административных мер (объединение, поглощение, ликвидация). Такие меры по структурному реформированию должны быть основаны на государственных отраслевых программах.

В-третьих, формировать институты, создающие в экономике обширный слой малых и средних инновационных фирм, способных не только создавать большое разнообразие инновационных продуктов, но и постоянно дифференцировать их структуру и коммерческую ориентацию. Современные научные и технологические процессы свидетельствуют, что самая высокая инновационная активность фиксируется в странах с высоким уровнем зрелых рыночных механизмов и предпринимательской среды, а также в странах, осуществивших быстрые структурные реформы. В странах, где государство имеет большую роль в экономике, внутренняя инновационная активность существенно слабее, и упор делается на привлечение зарубежных инноваций, что на первом этапе вполне естественно.

Это обусловлено тем, что быстрые структурные реформы сокращают период неопределенности и препятствуют мобилизации оппозиционных групп, способных блокировать реформы, а последовательные, в свою очередь, предполагают меньшие социальные издержки в коротком периоде, поскольку при их проведении избегают нарушения устоявшегося положения путем одновременного введения реформ во многих секторах экономики. При более детальном рассмотрении трансформационных переходных экономик, можно увидеть, что различия между быстрыми и последовательными реформами незначительны.

С помощью целенаправленной трансформации общество производит необходимые изменения, системные коррективы, с тем чтобы избежать накопления противоречий и их стихийного разрешения, При этом возникает необходимость поддержания относительной устойчивости системы на основе обеспечения регулируемости осуществляемых трансформаций.

Современные стратегии должны учитывать не только общие подходы к реформированию систем, но и традиционные национальные особенности. В самом начале этапа важно определить национальную стратегию в рамках которой в какой мере возможно использовать общие закономерности, свойственные экономическим системам, и особые подходы, определяемые условиями функционирования национальной системы. 


\section{ВЫВОДЫ}

Сущность трансформации состоит в изменении компонентов, параметров и пропорций и связей экономической системы в целях перехода в новое качественной состояние, связанное с изменением внутренней и внешней среды. Общая посылка заключается в том, что социально-экономические системы становятся трансформационными прежде всего в связи с исчерпанием потенциала развития, перехода к новому хозяйственному механизму, преодоления системных структурных деформаций, в силу низкого качества экономического роста. Вступление большой группы бывших социалистических стран в трансформационный период означало отказ от прежней модели экономического роста и формирование новой модели экономического роста, сущностными чертами, которой должны быть: обеспечение высокой экономической эффективности, четкая социальная направленность, в частности, создание условий, способствующих формированию среднего класса, восприимчивость к инновациям, органически вписаться в эволюцию мировохозяйственных связей в контексте глобализации.

Наряду с понятием «трансформация» при рассмотрении вопросов преобразования, реформирования экономических систем используются близкие понятия «модернизация» и «реструктуризации», однако они затрагивают отдельные частные мероприятия или локальные преобразования. В разных научных традициях эти вопросы трактуются по-разному. Так, понятие «реформирование» связывается с количественными изменениями параметров экономической системы. Более широкое трактовка вкладывается в понятие «модернизация». В трансформирующейся социально-экономической системе будем понимать модернизацию как продвижение к более конкурентоспособной экономике и обществу, к системе социальных отношений, способствующей развитию и становлению экономики для человека, реализации потенциала представителей разных социальных групп. В целом, все эти достаточно близкие по смыслу понятия отличаются мерой изменения по признаку накопления количественных изменений и перехода на новый качественный уровень.

Общее, что определяет трансформационную экономику каждой страны тоже быть выражено посредством 3 основных векторов: постепенное отмирание элементов реального социализма, вследствии их неэффективности; генезис отношений позднего капитализма в виде зависимых периферийных моделей; тенденции социализации, гуманизации и экологизации общественно-экономического развития. В рамках последней тенденции определяются конкретный черты и закономерности трансформационной экономики, что выражает новую парадигму социальноэкономического развития. Следует отметить, что основное содержание процессов трансформации определяется разработкой конкретно-исторических или страноведческих моделей, в полной мере учитывающих внутренние и внешние факторы современного развития страны, не допуская при этом неэффективного копирования упрощенных схем организации. Представляется, что национальная экономика в процессе трансформации должна учитывать не только общие, генетические черты перехода к смешанной экономике, но и определить собственную модель экономики переходного периода, учитывающей общенациональные стартовые условия построения долговременной стратегии развития экономики, без которой экономическая и политическая активность приобретает характер вялотекущих адаптационных действий, а обществу трудно выработать рациональное поведение.

Переход от обязательного условия к условию достаточному также является содержанием стратегии системной трансформации, охватывающей перестройку как основных макроэкономических политик (монетарной, фискальной, торговой, промышленной, научно-технической, общественной), так и перестройку системы 
функционирования экономики, а особенно рынка (институциональная оболочка, главные инструменты и механизмы распределения производственных факторов).

В целом, познание главных теоретических и методологических концепций (подходов) долговременного экономического роста и системных преобразований имеет значение не столько ретроспективное, сколько перспективное. Благодаря ему возможно более глубокое познание как шансов, так и угроз в развитии трансформирующихся стран, а на этой основе - формулирование выводов относительно экономической стратегии.

\section{ЛИТЕРАТУРА}

1. Лемешевский И.М. Национальная экономика Беларуси: основы стратегии развития /И.М. Лемешевский. - Минск: «ФУАинформ», 2012. - 70 с.

2. Karl Polani/ The Great Transformation: The political and economic Origin of Our Time, Boston, 1944.

3. Сазонова Г.А. Структурная трансформация экономических систем. Специальность 080005 - Экономика и управление народным хозяйством Диссертация на соискание степени д-р экон. наук. - Санкт-Петербург, 2002. - 396 с.

4. Львов Д.С. Экономика развития. М.: «Экзамен», 2009. - 253 с.

5. Минакир П.А. Системные трансформации в экономике.- Владивосток, $2009-158 \mathrm{c}$.

6. Глазьев С.Ю. Теория долгосрочного технико-экономического развития. М.: Владар, 1993. - 143c.

7. Бузгалин А.В. Теория социально-экономических трансформаций: прошлое, настоящее и будущее экономик «реального» социализма в глобальном постиндустриальном мире. // А.В. Бузгалин, А.И. Колганов, МГУ им. Ломоносова М.В. - М.: ТЕИС, 2003. $-486 \mathrm{c}$.

8. Шимов В.Н. Теоретические и практические аспекты структурной трансформации экономики Беларуси/ В.Н. Шимов // Белорусский экономический журнал - 2010. №2 - C. 10-19.

9. Арнольд В.И. Теория катастроф. - М.: «Экономика», 1990. - 249 с.

10. L. Balcerowicz, Rola i miejsce nauki w procesach transformacji. Referat. Konferencja Polskiej Akademii Nauk 28 maja 1999 r.

11. Paul M. Romer, Increasing Returns and Long-run Growth, „The Journal of Political Economy" 1986, vol. 94, p. 1002-1037; A. Young, Invention and Bounded Learning by Doing, "The Journal of Political Economy" 1991, vol. 101, p. 443-472; G. M. Grossman, E. Helpman, Endogenous Innovation in the Theory of Growth, „Journal of Economic Perspectives" 1994, vol.8, p. 23-44.

12. Ромуальд Полиньски. Трансформация экономических систем в Центральной и Восточной Европе/науч. ред. Никитенко П.Г. Минск: Право и экономика, 2004. - 261 с.

13. Норт Д. Институты, институциональные изменения и функционирование экономики. М.; Фонд экономической книги «Начало», 1997.

14. Плискевич Н.М. Возможности трансформации в России и концепция НортаУоллиса-Вайнгаста./ Н.М. Плискевич // Общественные науки и современность, 2013 №5. - С. 37-48.

15. Гумилев Л.Н. Струна истории. Лекции по этнологии/Лев Гумилев; составление, предисловие, комментарии О.Г. Новиковой.- 4-е изд.- М.; Айрис- пресс, 2011.- 608 с.

16. Гумилев Л.Н. Этногенез и биосфера земли/ Л.Н. Гумилев.- М.; Айварис- пресс, 2011. $-560 \mathrm{c}$.

Статья поступила в редакичию 18 декабря 2015 года. 